\title{
Prefrontal Serotonin Depletion Affects Reversal Learning But Not Attentional Set Shifting
}

\author{
H. F. Clarke, ${ }^{1}$ S. C. Walker, ${ }^{1}$ H. S. Crofts, ${ }^{1}$ J. W. Dalley, ${ }^{1}$ T. W. Robbins, ${ }^{1}$ and A. C. Roberts ${ }^{2}$ \\ ${ }^{1}$ Department of Experimental Psychology, University of Cambridge, Cambridge CB2 3EB, United Kingdom, and ${ }^{2}$ Department of Anatomy, University of \\ Cambridge, Cambridge CB2 3DY, United Kingdom
}

Recently, we have shown that serotonin (5-HT) depletion from the prefrontal cortex (PFC) of the marmoset monkey impairs performance on a serial discrimination reversal (SDR) task, resulting in perseverative responding to the previously correct stimulus (Clarke et al., 2004). This pattern of impairment is just one example of inflexible responding seen after damage to the PFC, with performance on the SDR task being dependent on the integrity of the orbitofrontal cortex. However, the contribution of 5-HT to other forms of flexible responding, such as attentional set shifting, an ability dependent on lateral PFC (Dias et al., 1996a), is unknown. The present study addresses this issue by examining the effects of 5,7-dihydroxytryptamine-induced PFC 5-HT depletions on the ability to shift attention between two perceptual dimensions of a compound visual stimulus (extradimensional shift).

Monkeys with selective PFC 5-HT lesions, despite being impaired in their ability to reverse a stimulus-reward association, were unimpaired in their ability to make an extradimensional shift when compared with sham-operated controls. These findings suggest that 5-HT is critical for flexible responding at the level of changing stimulus-reward contingencies but is not essential for the higher-order shifting of attentional set. Thus, psychological functions dependent on different loci within the PFC are differentially sensitive to serotonergic modulation, a finding of relevance to our understanding of cognitive inflexibility apparent in disorders such as obsessivecompulsive disorder and schizophrenia.

Key words: obsessive-compulsive disorder; schizophrenia; executive function; serotonin; attention; cognitive flexibility

\section{Introduction}

The serotonergic innervation of the prefrontal cortex (PFC) is implicated in the modulation of cognition and emotion and is of particular interest because of the association between serotonergic dysfunction and psychiatric illness. Specifically, dysregulation of prefrontal serotonin is hypothesized to contribute to the behavioral impairments associated with schizophrenia (Meltzer et al., 2003), depression (Meltzer, 1989), and obsessive-compulsive disorder (OCD) (Blier and de Montigny, 1998).

Recently, we found that selective 5,7-dihydroxytryptamine (5,7-DHT)-induced prefrontal 5-HT depletion in the marmoset monkey impaired performance on a serial discrimination reversal task, in which monkeys were required to shift their responding repeatedly between one of two stimuli. During reversal, lesioned monkeys displayed perseverative responding to the previously rewarded stimulus (Clarke et al., 2004). Performance of such reversal learning tasks preferentially activates the orbitofrontal cortex (OFC) in humans (Kringelbach and Rolls, 2003; O'Doherty et al., 2003), and, as well as being impaired in schizo-

Received Sept. 7, 2004; revised Nov. 19, 2004; accepted Nov. 22, 2004.

This work was supported by a Wellcome Trust program grant (T.W.R., B.J. Everitt, A.C.R., and B.J. Sahakian) and conducted within the Medical Research Council Centre for Behavioral and Clinical Neuroscience (Cambridge, UK). H.F.C. was supported by a Wellcome Trust Prize Studentship. We thank David Theobald for histochemical assistance and Rudolf Cardinal for valuable advice.

Correspondence should be addressed to Angela C. Roberts, Department of Anatomy, University of Cambridge, Downing Site, Cambridge CB2 3DY, UK. E-mail: acr4@cam.ac.uk.

DOI:10.1523/JNEUROSCI.3690-04.2005

Copyright $\odot 2005$ Society for Neuroscience $\quad$ 0270-6474/05/250532-07\$15.00/0 phrenia (Pantelis et al., 1999), is disrupted by orbitofrontal lesions in human and nonhuman primates (Jones and Mishkin, 1972; Rolls et al., 1994; Dias et al., 1996a,b; Fellows and Farah, 2003). Inflexible responding on a discrimination reversal task is one example of response rigidity seen after frontal lobe damage. Other examples, such as difficulties in shifting between higherorder attentional sets, are seen after extensive damage to dorsolateral and ventrolateral regions (lateral PFC) of PFC in humans (Milner, 1963; Rogers et al., 2000; Smith et al., 2004) and lateral PFC in monkeys (Dias et al., 1996a), as well as in schizophrenia and depression (Berman et al., 1986; Merriam et al., 1999). In attentional set shifting, instead of shifting responding between specific exemplars, such as in reversal learning, subjects are required to shift their attention between distinct perceptual dimensions of multidimensional stimuli (e.g., shapes and lines) to track stimulus-reward associations. In addition to differing in their cortical neuroanatomical loci within the PFC (i.e., orbitofrontal in the case of reversal learning and lateral PFC in the case of set shifting), these two types of shift may also differ in their modulation by ascending monoamine systems innervating the PFC. Thus, catecholaminergic depletion is known to affect attentional set-shifting performance but has no apparent effect on serial reversal learning (Roberts et al., 1994). In contrast, excitotoxic lesions of the nucleus basalis, which result in prefrontal cholinergic depletion, disrupt reversal learning but not attentional set shifting (Roberts et al., 1992).

Although 5-HT lesions of the PFC have been shown to disrupt 
reversal learning (Clarke et al., 2004), the contribution of prefrontal 5-HT to set shifting is unknown. However, given the efficacy of serotonergic drugs in ameliorating the symptoms of disorders in which set shifting is impaired (e.g., schizophrenia and depression), such information may provide valuable insight into the psychopathology of these disorders, as well as the parcellation of neurotransmitter function within the PFC. Therefore, this study investigates the effects of selective prefrontal 5-HT depletion in the marmoset on the performance of an attentional setshifting task. For comparison, performance was also examined on a subsequent test of discrimination reversal learning.

\section{Materials and Methods}

Subjects. Sixteen common marmosets (Callithrix jacchus; seven females, nine males) bred on site at the Medical Research Council (Cambridge, UK) research colony were housed in pairs. All of the monkeys were fed $20 \mathrm{~g}$ of MP.E1 primate diet (Special Diet Services, Essex, UK) and two pieces of carrot $5 \mathrm{~d}$ /week after the daily behavioral testing session, with simultaneous access to water for $2 \mathrm{~h}$. On weekends, their diet was supplemented with fruit, rusk, eggs, treats, and marmoset jelly (Special Diet Services), and they had ad libitum access to water. All of the procedures were performed in accordance with the United Kingdom Animals (Scientific Procedures) Act of 1986.

Apparatus. Behavioral testing took place within a sound-attenuated box in a dark room (for full experimental details, see Roberts et al., 1988). The animal sat in a Perspex (polymethyl methacrylate) transport box, one side of which was removed to reveal a color visual display unit (VDU) (model 1440; Microvitec, Bradford UK). The marmoset reached through an array of vertical metal bars to touch stimuli presented on the VDU, and these responses were detected by an infrared beam array (Microvitec Touchtec 501) attached to the screen. A reward of cooled banana milkshake (Nestlé, York, UK) was delivered to a centrally placed spout. Presentation of reward was signaled by a $4 \mathrm{kHz}$ tone played through loudspeakers located on either side of the VDU and was dependent on the marmoset licking the spout to trigger a peristaltic pump that delivered the milkshake. The test chamber was lit with a $3 \mathrm{~W}$ bulb. The stimuli presented on the VDU were blue shapes $(32 \times 32 \mathrm{~mm})$ and white lines $(32 \times 38 \mathrm{~mm})$, which were displayed to the left and right of the central spout. The stimuli were generated on an Acorn (Cambridge, UK) Archimedes computer, which also controlled the apparatus and recorded responding.

Behavioral testing. All of the monkeys were initially trained to enter a Perspex transport box for a marshmallow reward and were familiarized with the testing apparatus. Monkeys were then trained sequentially to collect a milkshake reward, to learn the tone-reward contingency, and to respond on the touchscreen until they were reliably and accurately making 40 responses to a square stimulus presented to the left and right of the licker in $20 \mathrm{~min}$.

Throughout behavioral testing, the monkeys were presented with a series of two-choice discriminations consisting of shapes, lines, or a combination of shapes and lines. A response to the correct stimulus resulted in the incorrect stimulus disappearing from the screen, whereas the correct stimulus remained present for the duration of a $5 \mathrm{~s}$ tone that signaled the availability of $5 \mathrm{~s}$ of reinforcement. Failure to collect the reward was scored as a missed reinforcement. A response to the incorrect stimulus caused both stimuli to disappear from the screen and a $5 \mathrm{~s}$ timeout period during which the houselight was extinguished. The intertrial interval was $3 \mathrm{~s}$, and, within a session, the stimuli were presented equally to the left and right sides of the screen. Each monkey was presented with 40 trials per day, $5 \mathrm{~d}$ /week and progressed to the next discrimination having attained a criterion of $90 \%$ correct in a session of 40 trials. If a monkey showed a significant side bias ( 10 consecutive responses to one side), a rolling correction procedure was implemented whereby the correct stimulus was presented on the nonpreferred side until the monkey had made a total of three correct responses.

The test stages were as follows (Fig. 1). (1) Two consecutive simple discriminations [simple discrimination 1 (SD1) and SD2], in which monkeys were presented with a pair of exemplars, either two blue shapes

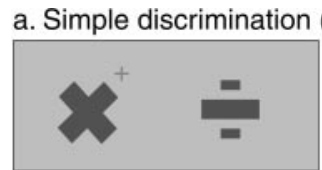

b. SD2

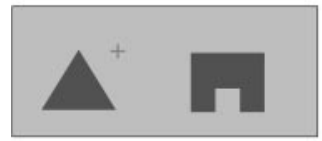

c. Compound Discrimination

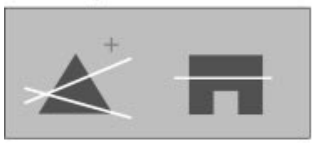

d. Intra-dimensional Shift (ID1)

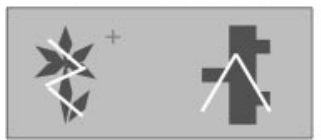

e. ID2
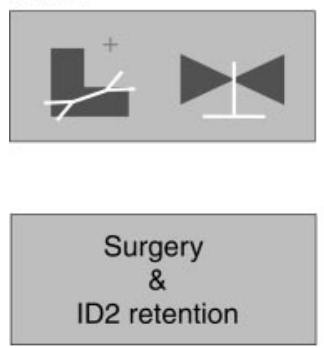

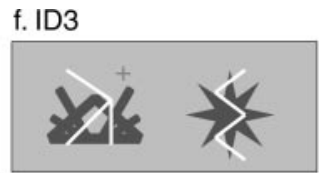

g. ID4

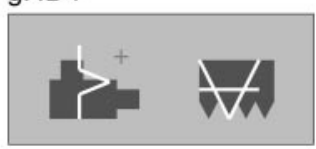

h. ID5

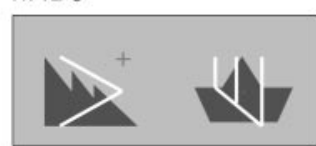

i. ID5 probe

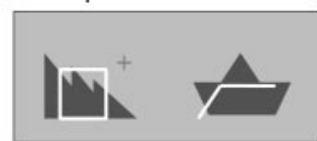

j. Extra-dimensional shift (EDS)

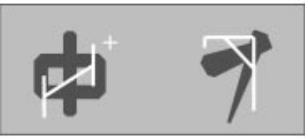

k. Reversal

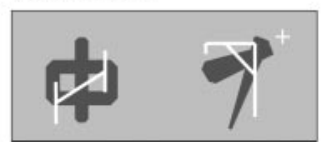

Figure 1. Stimulus exemplars from each stage of visual discrimination learning. On any one trial, exemplars from the relevant dimension were paired randomly with exemplars from the irrelevant dimension on either the left or the right of the screen. The rewarded exemplar is indicated by a + symbol, and the symbol color indicates whether the relevant dimension is shapes (blue) or lines (white). In the example shown here, the relevant dimension, up to the EDS stage, is shapes.

or two white lines. For each of the discriminations, one of the exemplars was paired with reward and one was not. One-half of the monkeys were initially presented with lines, and one-half were presented with shapes (Fig. 1a,b).

(2) A compound discrimination (CD), in which exemplars from the previously unseen dimension were introduced, so that the stimuli then consisted of white lines superimposed on blue shapes. On any one trial, one of the blue shapes (or white lines) was paired with one or other of the white lines (or blue shapes), such that, within a session, each blue shape (or white line) was paired equally often with each of the two lines (or blue shapes). For each monkey, the exemplars from the relevant dimension remained the same as in the previous simple discrimination (SD2), with the same exemplar associated with reward. Thus, the newly introduced dimension was irrelevant (Fig. 1c). For example, if a response to the blue triangle in SD2 was rewarded, a response to the blue triangle was still rewarded in $\mathrm{CD}$, regardless of which of the two alternating white lines was then superimposed on it.

(3) Two additional compound discriminations involving intradimensional shifts (IDSs) [intradimensional shift 1 (ID1) and ID2], each using two novel exemplars from both the relevant and irrelevant dimensions (Fig. 1d,e). For each monkey, whichever perceptual dimension had been relevant remained relevant, and they had to continue to respond to one of its exemplars.

(4) Surgery followed by an additional presentation of ID2 (retention test).

(5) Three additional novel compound discriminations (ID3-ID5), involving intradimensional shifts, as above (Fig. $1 f-h$ ). 
Table 1. Mean \pm SEM levels of serotonin, dopamine, and noradrenaline (expressed as picomoles per milligram of wet weight) in the frontal and cingulate cortices of the control group and the percentage depletion of serotonin ( \pm SEM) in marmosets with 5,7-DHT lesions of the frontal cortex

\begin{tabular}{|c|c|c|c|c|c|c|}
\hline \multirow[b]{2}{*}{ Region } & \multicolumn{2}{|l|}{ Serotonin } & \multicolumn{2}{|l|}{ Dopamine } & \multicolumn{2}{|l|}{ Noradrenaline } \\
\hline & Control level & $\%$ depletion & Control level & $\%$ depletion & Control level & $\%$ depletion \\
\hline OFC & $0.73 \pm 0.16$ & $73.8 \pm 2.21^{*}$ & $0.25 \pm 0.02$ & $19.5 \pm 9.22$ & $0.85 \pm 0.16$ & $7.90 \pm 14.3$ \\
\hline B9 & $0.70 \pm 0.17$ & $80.2 \pm 2.98^{*}$ & $0.21 \pm 0.02$ & $23.8 \pm 10.7$ & $0.83 \pm 0.12$ & $21.7 \pm 14.1$ \\
\hline MED & $0.96 \pm 0.23$ & $78.0 \pm 2.09^{*}$ & $0.24 \pm 0.03$ & $20.5 \pm 14.1$ & $1.01 \pm 0.15$ & $22.3 \pm 12.2$ \\
\hline B8 & $0.71 \pm 0.22$ & $64.8 \pm 3.62^{*}$ & $0.40 \pm 0.04$ & $19.6 \pm 12.7$ & $1.24 \pm 0.19$ & $10.9 \pm 14.6$ \\
\hline M/PM & $0.86 \pm 0.21$ & $53.8 \pm 4.86$ & $0.41 \pm 0.05$ & $15.4 \pm 7.84$ & $1.49 \pm 0.27$ & $-4.6 \pm 16.1$ \\
\hline C1 & $0.91 \pm 0.32$ & $67.6 \pm 6.02$ & $0.35 \pm 0.07$ & $21.2 \pm 6.49$ & $1.57 \pm 0.35$ & $18.2 \pm 10.4$ \\
\hline C2 & $0.84 \pm 0.26$ & $63.1 \pm 9.27$ & $0.23 \pm 0.03$ & $-0.1 \pm 12.3$ & $1.34 \pm 0.32$ & $5.49 \pm 18.9$ \\
\hline
\end{tabular}

${ }^{*} p<0.05$, significantly different from controls. MED, Pregenual medial PFC; M/PM, primary motor and premotor cortices; $C 1$, anterior cingulate cortex; $C 2$, midcingulate cortex. In all cases, $n=7$ because of loss of data from one control and one lesioned monkey.

(6) Distractor probe test, in which the exemplars from the relevant dimension and the specific exemplar-reward association remained unaltered, but the exemplars from the irrelevant dimension were replaced with novel exemplars (Fig. 1i).

(7) ID5 repeated until the $90 \%$ criterion was reattained.

(8) Extradimensional shift (EDS), in which another novel compound discrimination was presented except that, for the first time, an exemplar from the previously irrelevant dimension was paired with reward, and the previously relevant dimension became irrelevant (Fig. 1j). The stimuli presented in ID5 and the EDS were counterbalanced across animals.

(9) Extradimensional reversal, in which all of the exemplars remained the same as in the EDS, but the stimulus-reward pairing was reversed within the newly relevant dimension, such that the previously unrewarded exemplar was now rewarded (Fig. $1 k$ ).

Surgical procedure. Lesions of the serotonergic innervation of the PFC were made using 5,7-DHT (4.96 mm; Fluka BioChemika, Sigma, Poole, UK) in saline- $0.1 \% \mathrm{~L}$-ascorbic acid, as described previously (Clarke et al., 2004). To protect the noradrenaline (NA) and dopamine (DA) innervation, respectively, the noradrenaline uptake blocker nisoxetine $(25 \mathrm{mM}$; Sigma) and the DA uptake blocker 1-(2-(bis-(4-fluorophenyl) methoxy)ethyl)-4-(3-phenylpropyl)piperazine dihydrochloride (GBR 12909) (1.0 mM; Sigma) were administered concomitantly in the infusate.

Subjects were premedicated with ketamine hydrochloride $(0.05 \mathrm{ml}$ of a $100 \mathrm{mg} / \mathrm{ml}$ solution, i.m.; Pfizer, Kent, UK), anesthetized with Saffan (alphaxalone $0.9 \% \mathrm{w} / \mathrm{v}$ and alphadolone acetate $0.3 \% \mathrm{w} / \mathrm{v}, 0.4 \mathrm{ml}$, i.m.; Schering-Plough, Kenilworth, NJ), and given a $24 \mathrm{~h}$ prophylactic analgesic (Rimadyl; $0.03 \mathrm{ml}$ of $50 \mathrm{mg} / \mathrm{ml}$ carprofen, s.c.; Pfizer), before being placed in a stereotaxic frame especially modified for the marmoset (David Kopf Instruments, Tujunga, CA). Injections were made at 0.4 $\mu \mathrm{l} / 20 \mathrm{~s}$ into 20 sites bilaterally within the PFC using a 30 gauge cannula attached to a $10 \mu \mathrm{l}$ syringe (Hamilton Bonaduz AG, Bonaduz, Switzerland). Coordinates and volumes used have been described previously (Clarke et al., 2004). Sham surgery was identical, except for the omission of the toxin from the infusion. Postoperatively, all of the monkeys received the analgesic Metacam (meloxicam; $0.1 \mathrm{ml}$ of a $1.5 \mathrm{mg} / \mathrm{ml}$ oral suspension; Boehringer Ingelheim, Ingelheim, Germany), before being returned to their home cage for $10 \mathrm{~d}$ of "weekend diet" and water ad libitum to allow complete recovery before returning to testing.

Behavioral measures. The main measure of the monkeys' performance on the visual discriminations was the total number of errors made before achieving criterion of $\geq 90 \%$ correct (excluding the criterion day) on each discrimination. Additional measures recorded for each trial were (1) the latency to respond to the stimuli presented on the VDU (response latency), (2) the latency to collect the reward from the spout (lick latency), and (3) the left-right location of the response. In addition, the type of errors that were made during the reversal were classified as perseverative (in which responding to the previously correct stimulus was significantly above chance), chance, or learning (in which responding to the newly correct stimulus was at or above chance, respectively). Signal detection theory (Macmillan and Creelman, 1991) was used to establish the subjects' ability to discriminate correct from incorrect stimuli independently of any side bias that might have been present. The discrimination measure $\left(d^{\prime}\right)$ and the bias measure $(c)$ were calculated, and the normal cumulative distribution function $(\mathrm{CDF})$ was compared with the criterion values of a two-tailed $z$ test (each tail, $p=0.05$ ) to determine the classification of each session (perseveration, chance, or learning). Sessions in which $\operatorname{CDF}\left(d^{\prime}\right)<0.05$ were classified as perseverative; sessions in which $\operatorname{CDF}\left(d^{\prime}\right)>0.95$ were classified as learning; and sessions in which $0.05 \leq \operatorname{CDF}\left(d^{\prime}\right) \leq 0.95$ were classified as chance. Sessions in which $\operatorname{CDF}(c)<0.025$ or $\operatorname{CDF}(c)>0.975$ were considered biased but were not excluded, because $d^{\prime}$ is still a valid measure of discrimination (Clarke et al., 2004). Days on which subjects attained criterion were excluded, as was the $1 \mathrm{~d}$ for one monkey in which the correction procedure resulted in the correct stimulus being presented on the same side for all of the trials, rendering $d^{\prime}$ and $c$ incalculable.

Statistics. The behavioral results were subjected to ANOVA using SPSS version 11.0 (SPSS, Chicago, IL). ANOVA models are described in the form $A_{2} \times B_{2} \times\left(C_{3} \times S\right)$, where $A$ and $B$ are between-subjects factors of group and dimension, each with two levels (control-lesion and shapeline, respectively), $C$ is a within-subjects factor of error type with three levels (perseverative-chance-learning), and $S$ represents subjects (Keppel, 1991). Raw data did not display heterogeneity of variance and therefore was not transformed (Howell, 1997). Post hoc comparisons were made using simple main effects and Tukey's test, whereas tissue data were analyzed using a Student's $t$ test with the Sidak correction for multiple comparisons (Sidak, 1967).

Postmortem lesion assessment. The specificity and extent of the 5,7DHT lesion of the PFC was assessed by postmortem tissue analysis of monoamine levels in cortical and subcortical regions 4-11 months after the administration of 5,7-DHT, as described previously (Clarke et al., 2004). Tissue samples were homogenized in $200 \mu \mathrm{l}$ of $0.2 \mathrm{M}$ perchloric acid for $1.5 \mathrm{~min}$ and centrifuged at $6000 \mathrm{rpm}$ for $20 \mathrm{~min}$ at $4^{\circ} \mathrm{C}$. The supernatant $(75 \mu \mathrm{l})$ was subsequently analyzed using reversed-phase HPLC and electrochemical detection. Chilled $15 \mu \mathrm{l}$ samples were separated on a C18 silica-based analytical column $(100 \times 4.6 \mathrm{~mm} 3 \mu \mathrm{m}$ octadecylsilane) using a mobile phase $\left(13.6 \mathrm{~g} / \mathrm{L} \mathrm{KH}_{2} \mathrm{PO}_{4} \cdot \mathrm{H}_{2} 0,185 \mathrm{mg} / \mathrm{L}\right.$ octane sulfonic acid, and $18 \%$ methanol, $\mathrm{pH} 2.75$ ) delivered at $0.8 \mathrm{ml} /$ min. Tissue levels of 5-HT and 5-hydroxyindoleacetic acid were quantified using a dual-electrode analytical cell and electrochemical detector (Coulochem II; ESA, Chelmsford, MA) with electrode 1 set at $-150 \mathrm{mV}$ and electrode 2 set at $180 \mathrm{mV}$ (5014b analytical cell; ESA) with reference to a palladium electrode. The resultant signal was integrated using Chromeleon software (version 6.20; Dionex, Sunnyvale, CA). The HPLC system was calibrated using standards containing known amounts of 5-HT, NA, and DA.

\section{Results}

\section{Neurochemical analysis of postmortem tissue from control} and 5,7-DHT PFC-lesioned monkeys

5,7-DHT injections into the PFC produced substantial depletions of 5-HT in all of the prefrontal regions examined when measured between 4 and 11 months postoperatively (Table 1). Analysis by independent-samples $t$ test using the Sidak correction for multiple comparisons revealed significant reductions in 5-HT relative to sham controls in the OFC $\left(t_{(12)}=5.802 ; p<0.001\right)$, lateral granular PFC (B9) $\left(t_{(12)}=7.224 ; p<0.001\right)$, and dorsal granular 
Table 2. Mean \pm SEM total error scores for each discrimination up to, but not including, the EDS and subsequent reversal for control $(n=8)$ and lesioned $(n=8)$ monkeys

\begin{tabular}{|c|c|c|c|c|c|c|c|c|c|c|}
\hline & & & & & & & & & & \\
\hline & Preoperative & & & Postope & & & & & & \\
\hline & SD1 + SD2 & $C D$ & $\mathrm{ID} 1+\mathrm{ID} 2$ & ID2 ret & ID3 & ID4 & ID5 & Day 1 probe & Total probe & ID5 ret \\
\hline Sham & 246.75 & 84.88 & 345.13 & 16.63 & 108.75 & 143.50 & 92.00 & 6.125 & 9.13 & 6.00 \\
\hline \pm SEM & 46.50 & 21.97 & 78.41 & 3.53 & 26.98 & 47.29 & 23.38 & 1.33 & 2.13 & 3.29 \\
\hline Lesion & 217.50 & 75.00 & 379.13 & 31.50 & 87.63 & 227.63 & 123.38 & 7.25 & 19.63 & 2.50 \\
\hline \pm SEM & 42.28 & 19.39 & 52.69 & 16.00 & 34.70 & 25.05 & 31.86 & 0.77 & 3.86 & 1.73 \\
\hline
\end{tabular}

ret, Retention.

\section{A. Extra-Dimensional Shift}

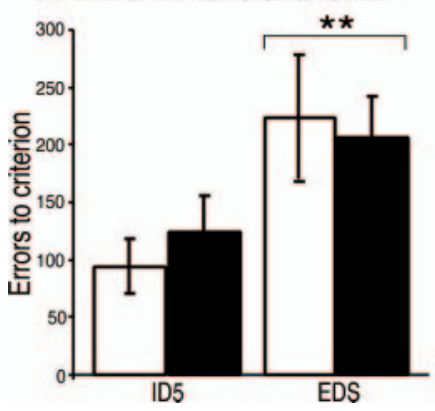

B. Reversal

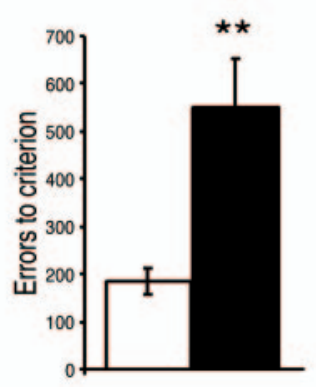

C. Reversal Error Type

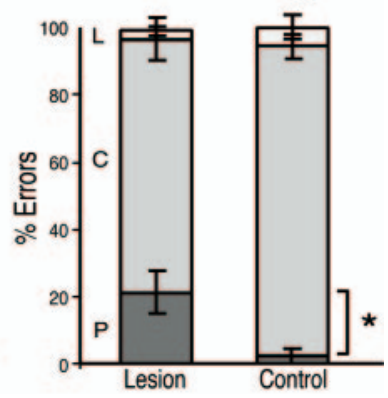

Figure 2. Mean \pm SEM number of errors to reach criterion on discriminations requiring an $\operatorname{IDS}, \operatorname{EDS}(A)$, and a reversal $(B)$ in control (white bars; $n=8$ ) and lesioned (black bars; $n=8$ ) groups. Although both lesioned and control groups made more errors to reach criterion on the EDS compared with the preceding IDS, their performance did not differ from one another. In contrast, the lesioned group made significantly more errors to reach criterion on the subsequent reversal $(B)$. Closer examination of the type of reversal errors made by the lesioned group $(P, C$, and $L$ are errors made while performance was significantly below chance, at chance, and above chance, respectively) revealed that the deficit was perseverative in nature ( $C$; for details, see Results). ${ }^{*} p<$ 0.05 , significantly different from controls; ${ }^{* *} p \leq 0.005$, significantly different from the IDS.

PFC (B8) $\left(t_{(12)}=3.855 ; p=0.002\right)$, according to Brodmann's architectonic map of the marmoset (Brodmann, 1909; Dias et al., 1997), as well as the pregenual medial PFC $\left(t_{(12)}=7.079 ; p<\right.$ $0.001)$. Consistent with the neuroanatomical localization of the 5-HT depletion to the PFC, no significant depletions of 5-HT were seen in other frontal or cingulate areas, including the primary motor and premotor cortex and the postgenual cingulate cortices. Depletions in these other areas were very variable across individuals and therefore were not significant as a group.

Administration of GBR 12909 and nisoxetine was successful at protecting the prefrontal dopaminergic and noradrenergic systems, respectively, because no region showed significant alterations in either DA $(p>0.05)$ or NA $(p>0.05)$ content.

\section{Behavioral assessment}

Preoperative discrimination learning

Preoperatively, marmosets destined to receive either selective 5-HT depletions of the PFC or control surgery did not differ in their ability to learn a series of visual discriminations (group and group $\times$ discrimination, $F<1$ ) (Table 2$)$.

\section{Postoperative discrimination learning requiring ID shifts}

Postoperatively, there was no significant difference among the groups in their ability to remember a previously learned visual discrimination (ID2 retention, $F<1$ ). Importantly, there was also no significant difference among the groups in their ability to perform three postoperative intradimensional shifts (ID3, ID4, and ID5, $\left.F_{(1,12)}=1.536 ; p=0.239\right)$, indicating that the lesion did not impair the ability to attend selectively to one dimension. A significant main effect of discrimination $\left(F_{(2,24)}=5.93 ; p=\right.$ $0.008)$ indicates that some discriminations were learned quicker (ID3) than others, but the lack of a discrimination $\times$ group in-

teraction $\left(F_{(2,24)}=1.809 ; p=0.185\right)$ indicates that the relative ease of different discriminations was matched across groups, with "shape relevant" discriminations being easier to learn than "line relevant" discriminations (discrimination $\times$ stimulus type, $\left.F_{(2,24)}=4.567 ; p=0.021\right)$.

\section{Postoperative performance on the} distractor test

On the first day of the distractor test, having reached criterion on ID5, both groups showed minimal disruption to responding to the correct stimulus in the presence of novel irrelevant stimuli $(F<1)$. However, the ability to reattain criterion performance was significantly impaired in the 5-HT-lesioned group $\left(F_{(1,15)}=5.671 ; p=\right.$ 0.032 ). There was no significant difference between groups in regaining criterion on the original ID5 $(F<1)$.

Postoperative discrimination learning requiring an extradimensional shift and stimulus reversal

Although 5,7-DHT lesions did not affect the acquisition of a novel discrimination requiring an EDS, there was a marked effect on the subsequent stimulus reversal, in which the 5-HT-lesioned animals made many more errors than controls. Repeatedmeasures ANOVA of errors to criterion of the final IDS (ID5) and subsequent EDS revealed no significant difference between the groups' ability to switch their responding to the previously irrelevant dimension $(F<1)$. All of the subjects made more errors in completing the EDS compared with the preceding IDS $\left(F_{(1,12)}=\right.$ 11.432; $p=0.005$ ) (Fig. $2 A$ ), confirming that the subjects did perform an attentional shift but that this did not differ between control and 5-HT-depleted subjects (group $\times$ discrimination, $F<1)$.

However, there was a marked impairment on the subsequent reversal, in which the previously unrewarded stimulus became rewarded and vice versa. Thus, a repeated-measures ANOVA of ID5, EDS, and reversal stages revealed a discrimination $\times$ group interaction $\left(F_{(2,24)}=12.092 ; p=0.0001\right)$. Subsequent simple main effects analysis revealed no effects of group for ID5 or EDS $(F<1)$ but a highly significant effect of group on the reversal stage $\left(F_{(1,15)}=67.105 ; p<0.0001\right)$ (Fig. $2 B$ ), reflecting a large increase in errors made by the lesioned monkeys to reverse. Close examination of the types of errors made by the lesioned monkeys during the reversal revealed that they made a higher percentage of perseverative errors than control monkeys (arcsine transformed data, $t_{(14)}=2.745 ; p=0.024$ ) (Fig. $2 C$ ), confirming the selective enhancement of perseverative responding by prefrontal $5-\mathrm{HT}$ depletion. 
Response latency and lick latency

Control and lesioned monkeys did not differ in their latencies to make correct or incorrect responses at any stage of the experiment $(F<1)$. Similarly, control and lesioned monkeys did not differ in their latency to obtain reward after a correct response at any stage $(F<1)$.

\section{Discussion}

The striking results of this study are that 5,7-DHT-induced depletion of 5-HT from the marmoset PFC produced deficits in visual discrimination reversal learning but not extradimensional set shifting. 5-HT depletion did not impair the ability to either acquire a discrimination that involved the shifting of an attentional set to the previously irrelevant dimension or acquire a series of discriminations requiring maintenance of a dimensional set learned preoperatively (intradimensional shifts), nor was the performance of a preoperatively acquired visual discrimination disrupted. However, as previously observed (Clarke et al., 2004), the lesion produced a severe, perseverative impairment in the monkeys' ability to reverse a stimulus-reward association. The lesion also produced a small but nevertheless significant increase in the number of errors to regain criterion on a distractor test in which novel exemplars replaced the existing irrelevant exemplars. These behavioral deficits were accompanied by a selective 5-HT depletion within the orbital $(73.8 \pm 2.21 \%)$, B9 (80.2 \pm $2.98 \%), \mathrm{B} 8(64.8 \pm 3.62 \%)$, and medial $(78.0 \pm 2.09 \%)$ regions of the PFC, 4-11 months postoperatively. Prefrontal levels of DA and NA were unaffected, as were monoamine levels in adjacent frontal and cingulate areas. That other forebrain areas, including the striatum, are unaffected by the lesion has been shown previously (Clarke et al., 2004). Together, these data demonstrate that prefrontal 5-HT is not important for higher-order shifting of attention, despite being critical for behavioral flexibility at the level of responding to altered stimulus-reward contingencies, highlighting the differential sensitivity of distinct prefrontal cognitive functions to serotonergic modulation. The mild impairment of 5-HT-lesioned animals on the distractor test may reflect a more general role for 5-HT in stimulus salience, as proposed by Oades (1997). In addition, these data extend our previous findings on discrimination reversal learning in which the deficit was not apparent until the second reversal (Clarke et al., 2004) and illustrate that the deficit can be observed on the first reversal. The apparent discrepancy between the two studies may be attributed to differences in the relative discrimination experience of the two cohorts of monkeys. After reaching the reversal stage, the monkeys in the current study had far more experience at visual discrimination learning than the monkeys reported previously. Thus, the failure to observe a deficit on the first reversal in the latter most likely reflects the overall poorer performance of the control monkeys on the first reversal, acting to mask any deficit in the lesioned group. Consequently, an accumulation of proactive interference over reversals is unlikely to account for the previously observed deficit because such an explanation cannot account for a deficit on the first reversal.

\section{Differential effects of serotonergic modulation on prefrontal tasks}

Because attentional set shifting and discrimination reversal learning are sensitive to lateral PFC and OFC damage, respectively, in humans and monkeys (Dias et al., 1996a; Rogers et al., 2000; Fellows and Farah, 2003), the insensitivity of set shifting to prefrontal 5-HT depletion (present study), coupled with the sensitivity of reversal learning (Clarke et al., 2004), supports the hy- pothesis that 5-HT is especially important in the regulation of OFC rather than lateral PFC function. Certainly, human studies have produced little evidence suggesting a role for 5-HT in laterally mediated processes. Thus, central 5-HT reductions induced by tryptophan depletion have little affect on dorsolateral or ventrolateral executive functions measured by Tower of London, attentional set-shifting, and spatial working-memory tasks (Park et al., 1994; Hughes et al., 2003). Although iontophoretic application of $5-\mathrm{HT}_{2 \mathrm{a}}$-selective agents altered the delay activity of rhesus macaque dorsolateral PFC neurons (Williams et al., 2002), 5-HT depletion from the rhesus principal sulcus induced by 5,6DHT produced no effect on working memory measured by spatial delayed alternation performance (Brozoski et al., 1979).

In contrast to the relative lack of effect on lateral PFC function, tryptophan depletion produces substantial deficits on tasks sensitive to OFC dysfunction, such as reversal learning and tests of decision making (Rogers et al., 1999a,b). Indeed, tryptophan depletion reduces subjects' ability to discriminate between rewards of different magnitudes (Rogers et al., 2003), mimicking the deficits in decision making caused by OFC lesions (Rogers et al., 1999a).

\section{Neurochemical regulation of attentional set shifting and reversal learning}

The finding that serotonergic depletion has no effect on attentional set shifting, yet impairs reversal learning, contrasts with previous studies examining central manipulation of catecholamine neurotransmitters. 6-Hydroxydopamine-induced DA and NA depletion of the marmoset PFC had no effect on either a serial or single reversal but enhanced extradimensional set shifting (Roberts et al., 1994), an effect probably attributable to impaired formation of a cognitive set, as suggested by impaired performance across a series of IDSs (Crofts et al., 2001). Consistent with a role for dopamine in set shifting, peripheral administration of the $\mathrm{D}_{2} / \mathrm{D}_{3}$ receptor antagonist sulpiride to human volunteers impaired extradimensional set shifting (Mehta et al., 1999), whereas an increase in dopaminergic activity induced by the catechol-Omethyltransferase inhibitor tolcapone is reported to enhance rat EDS performance (Tunbridge et al., 2004). Although systemic administration of the $\mathrm{D}_{2}$ agonist bromocriptine in humans and the constitutive "knock-out" of murine $\mathrm{D}_{2}$ receptors impair reversal learning (Mehta et al., 2001; Kruzich and Grandy, 2004), because of the global nature of these manipulations, these effects may depend on dopaminergic actions at the level of the striatum. Thus, although 5-HT may modulate prefrontal dopamine (Pehek et al., 2001), these data suggest that DA rather than 5-HT is important in the higher-order control of attention, whereas 5-HT is involved in the mechanism by which changes in the motivational significance of specific stimuli in the environment influence behavior.

Intact attentional set shifting but impaired on discrimination reversals have also been reported in marmosets with excitotoxic lesions of the cholinergic basal forebrain that resulted in PFC acetylcholine depletion (Roberts et al., 1992). Although systemic administration of the muscarinic antagonist scopolamine impairs both set shifting and reversals, again, not all of these effects may be frontally mediated (Chen et al., 2004). Investigations into the role of NA in the PFC have been limited, but central and systemic drug treatments have implicated the $\alpha 1$ and $\alpha 2$ receptors in attention and working-memory processes (Coull et al., 1995; Steere and Arnsten, 1997; Mao et al., 1999; Middleton et al., 1999). Thus, although these chemically defined arousal systems all seem to be active during exposure to stress (Arnsten and 
Goldman-Rakic, 1998; Maswood et al., 1998), they seem to have differential roles in set shifting and reversal learning and putatively in OFC and lateral PFC function. It is important to address whether these effects really are the result of differential modulation of distinct PFC regions that have independent functions or whether monoaminergic and cholinergic innervation promote different forms of processing within a single prefrontal region.

\section{Implications for the psychopathology of disease states}

The absence of attentional set-shifting deficits after 5-HT depletion has important implications for neuropsychiatric disorders in which EDS performance is impaired. Schizophrenia is characterized by deficits in set shifting (Weinberger et al., 1986; Pantelis et al., 1999), attention (Grillon et al., 1990), and working memory (Morice and Delahunty, 1996), and, consistent with a putative lateral locus for these executive dysfunctions, schizophrenics typically show hypoactivation of the dorsolateral PFC (Berman et al., 1986; Weinberger et al., 1986; Elliott et al., 1995). However, schizophrenics are also impaired at reversal learning because of perseveration at the previously correct stimulus (Elliott et al., 1995; Pantelis et al., 1999), a deficit associated with negative symptomatology (Yogev et al., 2003). Atypical antipsychotics, such as clozapine, relieve negative symptoms better than typical antipsychotics (Lee et al., 1994) and have a greater affinity for 5- $\mathrm{HT}_{2 \mathrm{a}}$ and 5- $\mathrm{HT}_{1 \mathrm{a}}$ receptors (Ichikawa et al., 2001). This, together with the current results, implicates 5-HT dysfunction in the perseverative phenomena associated with reversal impairments. In contrast, the intact set-shifting ability of 5-HT prefrontal-lesioned monkeys in the present study may explain why clozapine treatment in schizophrenia has inconsistent effects on set shifting and other attentional deficits (Goldberg et al., 1993; Hagger et al., 1993; Lee et al., 1994).

OCD is also associated with deficits in object alternation learning, another task sensitive to orbitofrontal dysfunction and related to reversal learning (Freedman et al., 1998), but, unlike in schizophrenia, set-shifting and working-memory deficits are inconsistent (for review, see Abbruzzese et al., 1997; Cavedini et al., 1998; Evans et al., 2004). The efficacy of the selective serotonin reuptake inhibitor paroxetine at ameliorating OCD symptoms suggests that 5-HT transporter inhibition is important in OCD treatment (Zohar and Judge, 1996). Although there is no clear evidence for underlying 5-HT dysfunction in OCD [but see recent reports of 5-HT transporter polymorphisms associated with OCD (Hemmings et al., 2003; Torres and Caron, 2003)], it is possible that 5-HT depletion within the OFC may mimic some of the pathophysiology of OCD. Thus, the reversal deficits in marmosets with prefrontal 5-HT depletion may provide a model of compulsive responding. Whether paroxetine will alleviate such deficits is currently unknown, but additional characterization of the 5-HT systems involved in this deficit may prove valuable in revealing potential targets for drugs that may be effective for OCD and certain symptoms of schizophrenia.

\section{References}

Abbruzzese M, Ferri S, Scarone S (1997) The selective breakdown of frontal functions in patients with obsessive-compulsive disorder and in patients with schizophrenia: a double dissociation experimental finding. Neuropsychologia 35:907-912.

Arnsten AF, Goldman-Rakic PS (1998) Noise stress impairs prefrontal cortical cognitive function in monkeys: evidence for a hyperdopaminergic mechanism. Arch Gen Psychiatry 55:362-368.

Berman KF, Zec RF, Weinberger DR (1986) Physiologic dysfunction of dorsolateral prefrontal cortex in schizophrenia. II. Role of neuroleptic treatment, attention, and mental effort. Arch Gen Psychiatry 43:126-135.
Blier P, de Montigny C (1998) Possible serotonergic mechanisms underlying the antidepressant and anti-obsessive-compulsive disorder responses. Biol Psychiatry 44:313-323.

Brodmann K (1909) Vergleichende Lokalisationslehre der Grosshirnrinde in ihren Prinzipien dargestellt auf Grund des Zellenbaues. Leipzig, Germany: Barth.

Brozoski TJ, Brown RM, Rosvold HE, Goldman PS (1979) Cognitive deficit caused by regional depletion of dopamine in prefrontal cortex of rhesus monkey. Science 205:929-932.

Cavedini P, Ferri S, Scarone S, Bellodi L (1998) Frontal lobe dysfunction in obsessive-compulsive disorder and major depression: a clinicalneuropsychological study. Psychiatry Res 78:21-28.

Chen KC, Baxter MG, Rodefer JS (2004) Central blockade of muscarinic cholinergic receptors disrupts affective and attentional set-shifting. Eur J Neurosci 20:1081-1088.

Clarke HF, Dalley JW, Crofts HS, Robbins TW, Roberts AC (2004) Cognitive inflexibility after prefrontal serotonin depletion. Science 304:878-880.

Coull JT, Middleton HC, Robbins TW, Sahakian BJ (1995) Clonidine and diazepam have differential effects on tests of attention and learning. Psychopharmacology 120:322-332.

Crofts HS, Dalley JW, Collins P, Van Denderen JC, Everitt BJ, Robbins TW, Roberts AC (2001) Differential effects of 6-OHDA lesions of the frontal cortex and caudate nucleus on the ability to acquire an attentional set. Cereb Cortex 11:1015-1026.

Dias R, Robbins TW, Roberts AC (1996a) Dissociation in prefrontal cortex of affective and attentional shifts. Nature 380:69-72.

Dias R, Robbins TW, Roberts AC (1996b) Primate analogue of the Wisconsin Card Sorting Test: effects of excitotoxic lesions of the prefrontal cortex in the marmoset. Behav Neurosci 110:872-886.

Dias R, Robbins TW, Roberts AC (1997) Dissociable forms of inhibitory control within prefrontal cortex with an analog of the Wisconsin Card Sort Test: restriction to novel situations and independence from "online” processing. J Neurosci 17:9285-9297.

Elliott R, McKenna PJ, Robbins TW, Sahakian BJ (1995) Neuropsychological evidence for frontostriatal dysfunction in schizophrenia. Psychol Med 25:619-630.

Evans DW, Lewis MD, Iobst E (2004) The role of the orbitofrontal cortex in normally developing compulsive-like behaviors and obsessivecompulsive disorder. Brain Cogn 55:220-234.

Fellows LK, Farah MJ (2003) Ventromedial frontal cortex mediates affective shifting in humans: evidence from a reversal learning paradigm. Brain 126:1830-1837.

Freedman M, Black S, Ebert P, Binns M (1998) Orbitofrontal function, object alternation and perseveration. Cereb Cortex 8:18-27.

Goldberg TE, Greenberg RD, Griffin SJ, Gold JM, Kleinman JE, Pickar D, Schulz SC, Weinberger DR (1993) The effect of clozapine on cognition and psychiatric symptoms in patients with schizophrenia. Br J Psychiatry 162:43-48.

Grillon C, Courchesne E, Ameli R, Geyer MA, Braff DL (1990) Increased distractibility in schizophrenic patients. Electrophysiologic and behavioral evidence. Arch Gen Psychiatry 47:171-179.

Hagger C, Buckley P, Kenny JT, Friedman L, Ubogy D, Meltzer HY (1993) Improvement in cognitive functions and psychiatric symptoms in treatment-refractory schizophrenic patients receiving clozapine. Biol Psychiatry 34:702-712.

Hemmings SM, Kinnear CJ, Niehaus DJ, Moolman-Smook JC, Lochner C, Knowles JA, Corfield VA, Stein DJ (2003) Investigating the role of dopaminergic and serotonergic candidate genes in obsessive-compulsive disorder. Eur Neuropsychopharmacol 13:93-98.

Howell DC (1997) Statistical methods for psychology, Ed 4, p 323. Belmont, California: Wadsworth.

Hughes JH, Gallagher P, Stewart ME, Matthews D, Kelly TP, Young AH (2003) The effects of acute tryptophan depletion on neuropsychological function. J Psychopharmacol 17:300-309.

Ichikawa J, Ishii H, Bonaccorso S, Fowler WL, O’Laughlin IA, Meltzer HY (2001) 5-HT(2A) and $\mathrm{D}(2)$ receptor blockade increases cortical DA release via 5-HT(1A) receptor activation: a possible mechanism of atypical antipsychotic-induced cortical dopamine release. J Neurochem 76:1521-1531.

Jones B, Mishkin M (1972) Limbic lesions and the problem of stimulusreinforcement associations. Exp Neurol 36:362-377. 
Keppel G (1991) Design and analysis: a researcher's handbook, Ed 3, pp 345-368. London: Prentice-Hall.

Kringelbach ML, Rolls ET (2003) Neural correlates of rapid reversal learning in a simple model of human social interaction. NeuroImage 20:1371-1383.

Kruzich PJ, Grandy DK (2004) Dopamine D2 receptors mediate two-odor discrimination and reversal learning in C57BL/6 mice. BMC Neurosci 5:12.

Lee MA, Thompson PA, Meltzer HY (1994) Effects of clozapine on cognitive function in schizophrenia. J Clin Psychiatry 55 [Suppl B]:82-87.

Macmillan NA, Creelman CD (1991) Detection theory: a user's guide. Cambridge, UK: Cambridge UP.

Mao ZM, Arnsten AF, Li BM (1999) Local infusion of an alpha-1 adrenergic agonist into the prefrontal cortex impairs spatial working memory performance in monkeys. Biol Psychiatry 46:1259-1265.

Maswood S, Barter JE, Watkins LR, Maier SF (1998) Exposure to inescapable but not escapable shock increases extracellular levels of 5-HT in the dorsal raphe nucleus of the rat. Brain Res 783:115-120.

Mehta MA, Sahakian BJ, McKenna PJ, Robbins TW (1999) Systemic sulpiride in young adult volunteers simulates the profile of cognitive deficits in Parkinson's disease. Psychopharmacology (Berl) 146:162-174

Mehta MA, Swainson R, Ogilvie AD, Sahakian J, Robbins TW (2001) Improved short-term spatial memory but impaired reversal learning following the dopamine $\mathrm{D}(2)$ agonist bromocriptine in human volunteers. Psychopharmacology (Berl) 159:10-20.

Meltzer H (1989) Serotonergic dysfunction in depression. Br J Psychiatry 155 [Suppl 8]:25-31.

Meltzer HY, Li Z, Kaneda Y, Ichikawa J (2003) Serotonin receptors: their key role in drugs to treat schizophrenia. Prog Neuropsychopharmacol Biol Psychiatry 27:1159-1172.

Merriam EP, Thase ME, Haas GL, Keshavan MS, Sweeney JA (1999) Prefrontal cortical dysfunction in depression determined by Wisconsin Card Sorting Test performance. Am J Psychiatry 156:780-782.

Middleton HC, Sharma A, Agouzoul D, Sahakian BJ, Robbins TW (1999) Idazoxan potentiates rather than antagonizes some of the cognitive effects of clonidine. Psychopharmacology (Berl) 145:401-411.

Milner B (1963) Effects of different brain lesions on card sorting. Arch Neurol 9:100-110.

Morice R, Delahunty A (1996) Frontal/executive impairments in schizophrenia. Schizophr Bull 22:125-137.

Oades RD (1997) Stimulus dimension shifts in patients with schizophrenia, with and without paranoid hallucinatory symptoms, or obsessive compulsive disorder: strategies, blocking and monoamine status. Behav Brain Res 88:115-131.

O’Doherty J, Critchley H, Deichmann R, Dolan RJ (2003) Dissociating valence of outcome from behavioral control in human orbital and ventral prefrontal cortices. J Neurosci 23:7931-7939.

Pantelis C, Barber FZ, Barnes TR, Nelson HE, Owen AM, Robbins TW (1999) Comparison of set-shifting ability in patients with chronic schizophrenia and frontal lobe damage. Schizophr Res 37:251-270.

Park SB, Coull JT, McShane RH, Young AH, Sahakian BJ, Robbins TW, Cowen PJ (1994) Tryptophan depletion in normal volunteers produces selective impairments in learning and memory. Neuropharmacology 33:575-588.

Pehek EA, McFarlane HG, Maguschak K, Price B, Pluto CP (2001) M100,907, a selective 5-HT(2A) antagonist, attenuates dopamine release in the rat medial prefrontal cortex. Brain Res 888:51-59.

Roberts AC, Robbins TW, Everitt BJ (1988) The effects of intradimensional and extradimensional shifts on visual discrimination learning in humans and non-human primates. Q J Exp Psychol B 40:321-341.

Roberts AC, Robbins TW, Everitt BJ, Muir JL (1992) A specific form of cognitive rigidity following excitotoxic lesions of the basal forebrain in marmosets. Neuroscience 47:251-264.

Roberts AC, De Salvia MA, Wilkinson LS, Collins P, Muir JL, Everitt BJ, Robbins TW (1994) 6-Hydroxydopamine lesions of the prefrontal cortex in monkeys enhance performance on an analog of the Wisconsin Card Sort Test: possible interactions with subcortical dopamine. J Neurosci 14:2531-2544.

Rogers RD, Everitt BJ, Baldacchino A, Blackshaw AJ, Swainson R, Wynne K, Baker NB, Hunter J, Carthy T, Booker E, London M, Deakin JF, Sahakian BJ, Robbins TW (1999a) Dissociable deficits in the decision-making cognition of chronic amphetamine abusers, opiate abusers, patients with focal damage to prefrontal cortex, and tryptophan-depleted normal volunteers: evidence for monoaminergic mechanisms. Neuropsychopharmacology 20:322-339.

Rogers RD, Owen AM, Middleton HC, Williams EJ, Pickard JD, Sahakian BJ, Robbins TW (1999b) Choosing between small, likely rewards and large, unlikely rewards activates inferior and orbital prefrontal cortex. J Neurosci 19:9029-9038.

Rogers RD, Andrews TC, Grasby PM, Brooks DJ, Robbins TW (2000) Contrasting cortical and subcortical activations produced by attentional-set shifting and reversal learning in humans. J Cogn Neurosci 12:142-162.

Rogers RD, Tunbridge EM, Bhagwagar Z, Drevets WC, Sahakian BJ, Carter CS (2003) Tryptophan depletion alters the decision-making of healthy volunteers through altered processing of reward cues. Neuropsychopharmacology 28:153-162.

Rolls ET, Hornak J, Wade D, McGrath J (1994) Emotion-related learning in patients with social and emotional changes associated with frontal lobe damage. J Neurol Neurosurg Psychiatry 57:1518-1524.

Sidak Z (1967) Rectangular confidence regions for the means of multivariate normal distributions. J Am Stat Assoc 62:623-633.

Smith AB, Taylor E, Brammer M, Rubia K (2004) Neural correlates of switching set as measured in fast, event-related functional magnetic resonance imaging. Hum Brain Mapp 21:247-256.

Steere JC, Arnsten AF (1997) The alpha-2A noradrenergic receptor agonist guanfacine improves visual object discrimination reversal performance in aged rhesus monkeys. Behav Neurosci 111:883-891.

Torres GE, Caron MG (2003) Center stage for the serotonin transporter: a gain-of-function polymorphism in persons with obsessive-compulsive disorder. Mol Pharmacol 64:196-198.

Tunbridge EM, Bannerman DM, Sharp T, Harrison PJ (2004) Catechol-Omethyltransferase inhibition improves set-shifting performance and elevates stimulated dopamine release in the rat prefrontal cortex. J Neurosci 24:5331-5335.

Weinberger DR, Berman KF, Zec RF (1986) Physiologic dysfunction of dorsolateral prefrontal cortex in schizophrenia. I. Regional cerebral blood flow evidence. Arch Gen Psychiatry 43:114-124.

Williams GV, Rao SG, Goldman-Rakic PS (2002) The physiological role of 5-HT2A receptors in working memory. J Neurosci 22:2843-2854.

Yogev H, Hadar U, Gutman Y, Sirota P (2003) Perseveration and overswitching in schizophrenia. Schizophr Res 61:315-321.

Zohar J, Judge R (1996) Paroxetine versus clomipramine in the treatment of obsessive-compulsive disorder. OCD Paroxetine Study Investigators. Br J Psychiatry 169:468-474. 